Check for updates

The BMJ

Cite this as: BMJ 2021;375:n2959 http://dx.doi.org/10.1136/bmj.n2959 Published: 01 December 2021

\title{
Covid-19: Poorly controlled asthma increases risk of hospital admission among children sixfold, finds study
}

\section{Elisabeth Mahase}

Children with poorly controlled asthma are at a higher risk of being admitted to hospital with covid-19 and should therefore be prioritised for vaccination, according to researchers who analysed data on 750 ooo children.

The Scottish study looked at five to 17 year olds with poorly controlled asthma, defined as those who have been admitted to hospital with asthma or prescribed two or more courses of oral steroids within the past two years, and found they were between three and six times more likely to be admitted to hospital with covid-19 compared with those without asthma.

As a result, the researchers are calling for unvaccinated children with poorly controlled asthma to be prioritised for covid-19 vaccination, including those aged five and older-an estimated 109488 children across the UK. Currently, only children 12 years or older are eligible for covid-19 vaccination in the UK.

The analysis, which covered the period between March 2020 and July 2021, was performed at the request of the UK's Joint Committee on Vaccination and Immunisation and used Scotland's national Early Pandemic Evaluation and Enhanced Surveillance of Covid-19 platform.

In total, 752867 children aged five to 17 years old were included in the analysis, which is published in Lancet Respiratory Medicine. Among 63463 children with a diagnosis of asthma, $4339(6.8 \%)$ had a confirmed SARS-CoV-2 infection and 67 (1.5\%) were admitted to hospital with covid-19. There were nine intensive care admissions or deaths in children. Among the children without asthma 40231 (5.8\%) had a confirmed SARS-CoV-2 infection and 382 (0.9\%) needed hospital treatment.

After adjusting for factors such as age, sex, socioeconomic status, other illnesses or conditions, and previous non-asthma related hospital admissions, researchers found that children who had recently been admitted to hospital with asthma were six times more likely to be admitted to hospital with covid-19 than those without asthma, while children who had recently been prescribed oral steroids faced a three times higher risk of hospital admission.

Co-author Ting Shi, research fellow at the University of Edinburgh, said, "Although covid-19 tends to affect children less severely than adults, our findings underscore the importance of carefully monitoring these children if they become infected with covid-19 and ensuring that children take their preventive inhalers regularly, go for asthma reviews, and have an up-to-date asthma treatment action plan. More research is needed to investigate the underlying mechanisms that predispose children to these increased risks of hospital admission with covid-19."

The authors highlighted some limitations to their study, including that asthma control may have changed over the two year study period, because of changes in behaviours or difficulties accessing care during the pandemic. In addition, the researchers were unable to account for some potentially important factors, such as tobacco exposure, unsuitable housing, and ethnicity.

The study was funded by UK Research and Innovation, the Research and Innovation Industrial Strategy Challenge Fund, Health Data Research UK, and the Scottish government.

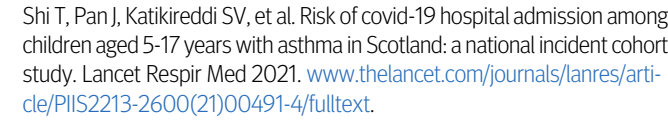

Shi T, Pan J, Katikireddi SV, et al. Risk of covid-19 hospital admission amon children aged 5-17 years with asthma in Scotland: a national incident cohort study. Lancet Respir Med 2021. www.thelancet.com/journals/lanres/article/PIIS2213-2600(21)00491-4/fulltext.

This article is made freely available for use in accordance with BMJ's website terms and conditions for the duration of the covid-19 pandemic or until otherwise determined by BMI. You may use, download and print the article for any lawful, non-commercial purpose (including text and data mining) provided that all copyright notices and trade marks are retained. 